\title{
Evaluation of some Indices Selection Traits of the "HS314" Genotype as a New Interspesific Hybrid Rootstock for Stone Fruit Trees
}

\author{
*11 JALIL, DEJAMPOUR; HAMID, RAHNEMOUN; HOSSIN, FATHI
}

\author{
Horticulture Crops Research Department, East Azarbaijan Agricultural and Natural Resources, AREEO, Tabriz, Iran
}

\begin{abstract}
Interspecific hybrids, especially in prunus genus, are used as rootstocks for stone fruit trees in the world, in recent decades. In this research, 106 interspesific hybrids including: almond $\times$ peach $(P$. amygdalus $\times P$. persica $)$, almond $\times$ prune $(P$. amygdalus $\times P$. cerasifera $)$, apricot $\times$ prune $(P$. armeniaca $\times P$. cerasifera $)$ and apricot $\times$ plum $(P$. armeniaca $\times P$. domestica ) were evaluated according to their vegetative and reproductive characteristics. "HS314" is a hybrid of Almond $\times$ peach, that was selected as clonal rootstock among this prunus population from 1995. In order to releasing of this genotype, some important traits as indices selection like; suckering, stability in soil, environment stress tolerance, graft compatibility, rooting of cutting, micropropagation and salt tolerance were evaluated. The results showed this rootstock had good graft compatibility with almond and peach and some apricot. Rooting of micro cutting and cutting was successful via in vitro (65-70 percent) and in vivo (50 percent) conditions. This genotype with strong and deeper roots had good stability in sandy and rocky soil. The salinity tolerance of "HS314" plantlet was 3-4 dSm-1. This genotype also had normal bearing and fruit set with nonedible fruits. @ JASEM
\end{abstract}

http://dx.doi.org/10.4314/jasem.v20i4.13

Keywords: rootstock, clonal, almond $\times$ peach, prunus

Clonal rootstocks are used for both industrial and modern fruit growing systems, interspecific hybrids, especially prunusgenuses, are considered as rootstocks for stone fruit trees. Most almond $\times$ peach hybrids were grafted compatible with all tested cultivars of peach, almond and some apricot or plum. Based on this, the selection of a perfect individual from rootstock is important for a tree and climaticthan scion (5 and 20). In recent decades, understanding the importance of fruit tree individuals in modern fruit planting hasdrawnlots of attention to the breeding of cultivars and rootstocks. So that, similar to studying the breeding of varieties', the research on rootstocks' breeding is seriously continued (9 and 13). Recent studies in developed countries haveled to the introduction of several individual rootstocks with desirable traits, such as the capacity foran increase ingrowth, dwarf trees, resistance to environmental stress, soil and disease, which are available for producers. Vegetative interspecifictraitsof almond and peach, including GF677, GF557, Hansen 36, Hansen 268, Adafuel, Ishtara (as multi-hybrid) are some typical examples of such rootstocks $(16,18$ and 23).New modified hybrid or multi-hybrid rootstocks, particularly for the genuses of Prunus, are available in different countries, with different goals, which are currently used in the business. For example, in Fruit Research Institute,minisk, Belarus, the main objective of tree breeding is to obtain resistance to coldness in winter. In this regard, the very resistant rootstocks such as Mara $(P$. cerasifera $\times P$. salicina $) \times P$. Iranica had been obtained, which is as a result of crossing several interspecific hybrids. These types of rootstocks are mostly sterile and infertile due to chromosomal imbalance, and are only used as individuals on interindividuals. In the case of stone fruit trees and almonds, the vegetative rootstocks of GF 677,the natural hybrid of peach and almond from the INRA Station in France was introduced for the first time. This hybrid is an excellent rootstock for different varieties, such as peach, nectarine and almond, especially for the conditions in Iran (4 and 19).

A number of hybrid and multi-hybrid rootstocks of Prunushave been achieved in the French research station, for example, the clone rootstock of Ishtarahasresulted from $[(P$. cerusifena $x P$. persica $) \mathrm{x}$ ( $P$. cerasifura $x$ P. saliciua) $]$, and is considered as a proper almond rootstock. Other multi-hybrids of Prunusare Viking andAtlaswhichcan be used as rootstocks (17, 20 23). Researches on fruit trees in Iran, especially stone fruit trees, have focusedon the collection and breeding cultivars, until recent years, and researches on the breeding of rootstocks of stone fruit trees is very low. However, because of the importance of rootstocks, work in this area should begivenpriority in the research programs of all fruit trees.

In breeding, the most important characteristics of the screening and selection of rootstocks for stone fruit trees include, easy vegetative reproduction, having strong roots, the development and growth conditions of seedlings in the nursery, lack of suckering, high efficiency in absorbing nutrients and water, good establishment in the soil, early and morebearing 
inducing, easy transferring of seedlings in replanting, good consistency, water scarcity and drought conditions, tolerance to soil pests and diseases. The use of consistent and sustained rootstocks is required for the development of cultivars in different climatic conditions and areas (3 and 24).This study focuses on the need for modification and access to various rootstocks with different characteristics and consistency. Breedingof rootstocks with specific traits requirethe use of intra- and interspecific crosses of useful and resistant genes and its transferanceto the desired rootstocks to achieve new and recombinant rootstocks.

In addition to the study and collection of natural hybrids using targeted artificial crosses, an attempt was made to develop a wide diversity and identify the growth characteristics and morphology after genotypes in this breeding and national project, For example, the two species of prune and plum from Prunushave the capability for vegetative reproduction, tolerance to high soil moisture and root suffocation, tolerance to root and collar decay. The species of Amygdalushave strong and deep roots, tolerant to calcareous and rocky soils, and is sensitive to both root decay and root and collar suffocation. Among hybrids derived from crosses between these two species, some genotypes possess the good traits of both species (9).

\section{MATERIALS AND METHODS}

Some promising rootstocks were selected from the population derived from crosses between different species of Prunusgenus(almond, apricot, peach, prune and plum) after screening and evaluationin Sahand Horticultural Research Station in 1998. "HS314," a hybrid of an Almond $\times$ peach, was selected due to its distinct distinct characteristics in terms of the rootstocks, this genotype was selected as a promising rootstock after field and the laboratory examination over 15 years. Some important selecting indices of these rootstocks, which were considered in the evaluation, were relative resistance to pests and diseases, resistance to cold, growth vigor, growth habits in nursery, salt tolerance, graft compatibility, climatic compatibility, establishment in soil, lack ofsucker, easy vegetative propagation by cuttings and in vitro culture $(5,23)$.

Micropropagation and in vitro propagation of this genotype was studied in the Biotechnology Research Institute of Tabriz (the North West of Iran)from 2003 to 2007 , during which the most appropriate medium and hormonal combination for the establishment, proliferation and rooting were examined. After examinations, 4 media (modified $\mathrm{MS}^{1}, \mathrm{WPM}^{2}, \mathrm{DKW}^{3}$ and modified Knop) using hormonal treatments of BAP $(0,0.5,1 \mathrm{mg} / \mathrm{l})$ and NAA $(0.5 \mathrm{mg} / \mathrm{l})$ were provided for two phenological stages of plants in spring and autumn (1, 10 and 12).

To assess the salinity, the pot culture and soil with salinity levels of $0,3,6,9 \mathrm{dSm}^{-1}$ using salts combination of $\mathrm{MgSO} 4, \mathrm{NaCl}, \mathrm{Na} 2 \mathrm{SO} 4$ and $\mathrm{CaCl} 2$, were used, respectively, with ratios of 12/8, 11/1, 10/2 and $20 / 7(11)$. In this experiment, the amount of total chlorophyll, chlorophyll a, chlorophyll b, of leaves' chlorophyll index, amino Acid Proline content, fresh and dry weight of leaves, stems and roots, as well as the concentration of $\mathrm{Mg}^{2+}, \mathrm{Cl}^{-}, \mathrm{Na}^{+}$and $\mathrm{Na} / \mathrm{k}$ were determined as evaluation indices. For a better comparison, the cultivar of Sahand almond and GF677 were used as a control (2,11 and 25).

In order to investigate the graft compatibility $f$ different varieties of almonds, apricots, tomatoes, plums and peach on this rootstock, sprout grafting with three replications from each varieties were considered and their compatibility in terms of survival and strength of the bond, swell of the bond, growth vigor of the scions ${ }^{4}$, chlorosis and quality and quantity of fruit were studied for 11 years (5).

To determine the possibility of proliferation of these rootstocks, woody cuttings in Perlite and IBA with concentrations of 1000, 1500 and 2000 ppm were used for 7-10 seconds. It is noteworthy that it was tried to use almond, apricot, plum and prune trees and hybrid GF677 as controls in all evaluations (4 and 24).

Evaluation of growth characteristics, resistance to pests and diseases, resistance to cold, establishment in soil and suckering performed on the basis of the related UPOV international guideline and IBPGIR descriptor and observation (4).

\section{RESULTS AND DISCUSSION:}

According to the recombination of interspecific hybridization, there were different morphogenetic traits among hybrid trees. Therefore, the first step in the study of this stand was to record morphological, reproductive and growth characteristics. Genotype "HS314" as a hybrid of peach and almond ( $P$. amygdalus $\times P$. Persica) had average traits and morphology of both parents. It had nonedible fruits but

\footnotetext{
1-Murashige and Skoog

2-Woody Plant Medium

${ }^{3}$-Driver and Kuniyuki 1984 (Walnut)
} 
high productivity like GF677. The morphological characteristics such as tree's vigor, leaf shape and size, flowers, productivity, fruits, petioles, falling date, awaken date of flower buds and vegetative buds are shown in Table 1 and Figure 1

Table 1: Comparison between some vegetative and reproductive characteristics of "HS314" and other stone fruit

\begin{tabular}{|c|c|c|c|c|c|c|c|c|c|c|c|}
\hline genotype & budsize & buddensity & anthernumber & pistillength & stamen length & $\begin{array}{l}\text { Difference between } \\
\text { stamen and pistillength }\end{array}$ & $\begin{array}{l}\text { flower size } \\
\text { andproductivity }\end{array}$ & $\begin{array}{l}\text { petal } \\
\text { color }\end{array}$ & $\begin{array}{l}\text { Flower } \\
\text { shape }\end{array}$ & $\begin{array}{l}\text { tree vigor } \\
\text { and leaves shape }\end{array}$ & Typeoffruit \\
\hline HS314 & $7.097 \mathrm{EF}$ & $1.33 \mathrm{E}$ & $50.33 \mathrm{~A}$ & $1.4 \mathrm{~B}$ & $1.7 \mathrm{~B}$ & $-0.3 \mathrm{~F}$ & $3.57 \mathrm{C}$ & Rosacea & $\begin{array}{l}\text { White/ } \\
\text { average }\end{array}$ & Strong/ elongated & Non-edible drupe \\
\hline $\begin{array}{l}\text { Almond } \\
\text { (Sahand } \\
\text { CV.) }\end{array}$ & $9.52 \mathrm{C}$ & $1.71 \mathrm{CD}$ & $48.66 \mathrm{~A}$ & $2 \mathrm{~A}$ & $1.5 \mathrm{D}$ & $0.5 \mathrm{CD}$ & $4.93 \mathrm{~A}$ & Rosacea & white & Average/ elongated & Edible \\
\hline Peach & $11.83 \mathrm{~B}$ & $0.07 \mathrm{~F}$ & $40 \mathrm{~B}$ & $1.42 \mathrm{~B}$ & $1.6 \mathrm{C}$ & $-0.18 \mathrm{~F}$ & $3.61 \mathrm{C}$ & Rosacea & white & Average/ elongated & drupe edible \\
\hline $\begin{array}{l}\text { prune } \\
\text { (Wild) }\end{array}$ & $5.45 \mathrm{G}$ & $2.11 \mathrm{~B}$ & $22 \mathrm{D}$ & $0.88 \mathrm{C}$ & $0.53 \mathrm{H}$ & $0.35 \mathrm{E}$ & $1.43 \mathrm{~F}$ & Rosacea & white & Average/ wide & drupe edible \\
\hline Apricots & $13.59 \mathrm{~A}$ & $2.11 \mathrm{~B}$ & $34.66 \mathrm{C}$ & $1.98 \mathrm{~A}$ & $1.18 \mathrm{E}$ & $0.8 \mathrm{~B}$ & $2.46 \mathrm{DE}$ & Rosacea & white & Average/ wide & drupe edible \\
\hline
\end{tabular}

Studying the population of 106 rootstocks of Prunus resulting from interspecific hybridizations showed that each genotype with high genetic diversity, in turn, had unique characteristics and had gained different scores during 15 years of assessments. The indices that had gained the most attention for selection of fruit trees and rootstock of "HS314" had most them, were very good climate adaptation of these trees to the climate conditions of the area in terms of the onset of leaf blight and tolerance to the cold of winter and heat of summer. In other words, the vitality of the trees throughout year and the absence of physiological and morphological side effects such as weak growth, chlorosis, frost of twigs or cracking of trunks, and loss of buds. were the primary criteria for selection.

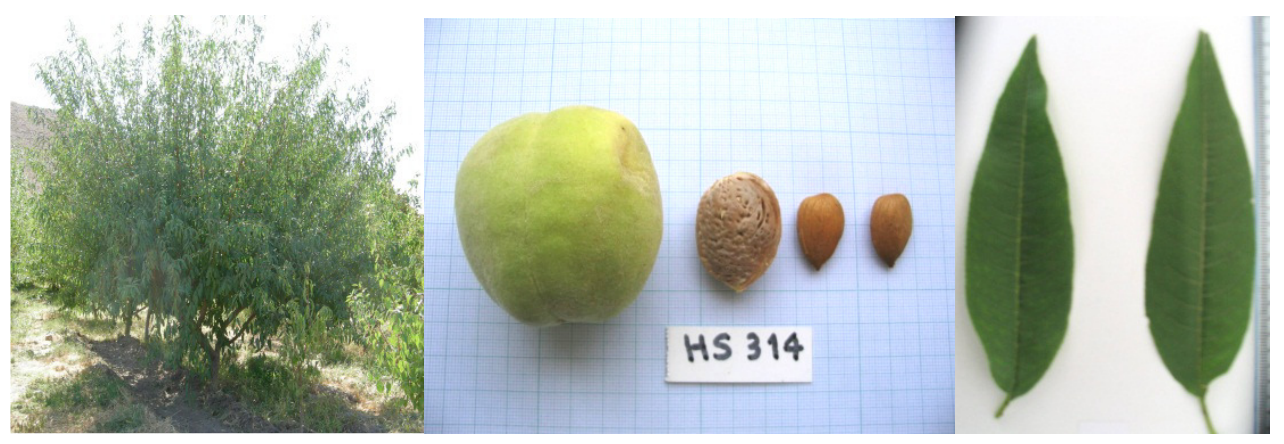

Fig 1.The form of leaves, fruits and tree of "HS314"

In addition, the trees showed resistance against all pests and diseases in the area and maintained their health without any physico-chemical control during the 15 years. Some most common pests and diseases areAphidaes,Lecaniumcorina,Peach\&Twigborer,Shoth oleborer, Root and crown rotcaused by Phytophthora and Armillariamellea.

This rootstockwas without any choppices or sprouts with a very good and solid establishment in soil. The roots of this genotype were very strong and deep as well as diffuse and had good hairy roots that were effective for survival rate and transmission.

"HS314" showed a good tolerance to salinity stress, which the experiments indicated that "HS314" from almonds, peaches and apricots are more resistant and tolerant salinity up to $3 \mathrm{dSm}^{-1}$. As it was found that salinity had negative effects on the chlorophyll content of leaves, leaf area, root and shoot dry weight. Although proline concentration increased with increasing in salinity levels (Table 2), but in this case the genotypes showed different responses. In this respect, similar results had been reported by Najafiet al. (2008) on two bitter almonds ${ }^{5}$. Physiological and morphological responses of the plants were often significant in high salinity levels (6 and $9 \mathrm{dSm}^{-1}$ ); however, negative effects on growth parameters were not observed at low salinity levels $\left(1.5\right.$ and $\left.3 \mathrm{dSm}^{-1}\right)$. It is noteworthy that fruit trees' tolerance to salinity is usually determined based on the vegetative growth and the tolerance to salinity for almond, apricot and plum was about $1.5 \mathrm{dSm}^{-1}(2,11$ and 25). Changes in proline were significant at different salinity levels. 
However, the lowest and highest values were related to Sahand almonds and "HS314", respectively. The total Chlorophyll and chlorophyll b significantly decreased with increasing in salinity levels, which was not significant for chlorophyll a (Table 2).
Furthermore, the effects of salinity of various concentrations of $\mathrm{K}^{+}, \mathrm{Mg}^{2}{ }^{+}, \mathrm{Ca}^{2}{ }^{+}, \mathrm{Na}^{+}$and $\mathrm{Cl}^{-}$on roots and leaves of genotypes were different. Thus, the values of $\mathrm{Mg}, \mathrm{Cl}$ and $\mathrm{Ma}$ as well as the ratio of $\mathrm{Na} / \mathrm{k}$ in leaves were reduced by salinity for all genotypes.

Table 2.Effect of salinity on some growth traits, proline, chlorophyll and chlorophyll index for "HS314" and

** Significant at $0.01 \%$ level

* Significant at $0.05 \%$ level Ns: not significant

To evaluate the ability of vegetative reproduction, which is considered as the most important index and determining factor in the selection of clonal rootstocks, several methods were used. The results of the multi-year study showed that this rootstock had very good micropropagation and rooting potentials. Hence, the most appropriate in vitro culture medium for the establishment and proliferation of "HS314" was WPM with the hormonal combination of BAP (1 $\mathrm{mg} / \mathrm{l})$ and IBA (0.01 mg/l) (Fig. 2).
These rootstocks were placed in WPM mediums with concentrations of 1 and $2 \mathrm{mg} / \mathrm{l}$ IBA plus 7 days of darkness and the rooting percents were 65 and $70 \%$, respectively, especially by the saturation of the bottom of explants (Fig 3 and 4). The results of this study are consistentwithCos et al. (7 and 8) on Pollizo V4, a hybrid of peach and almond. Therefore, these researchers recommended the hormonal saturation of the bottom of explants of recalcitrant genotypes and obtained the highest rooting percent 


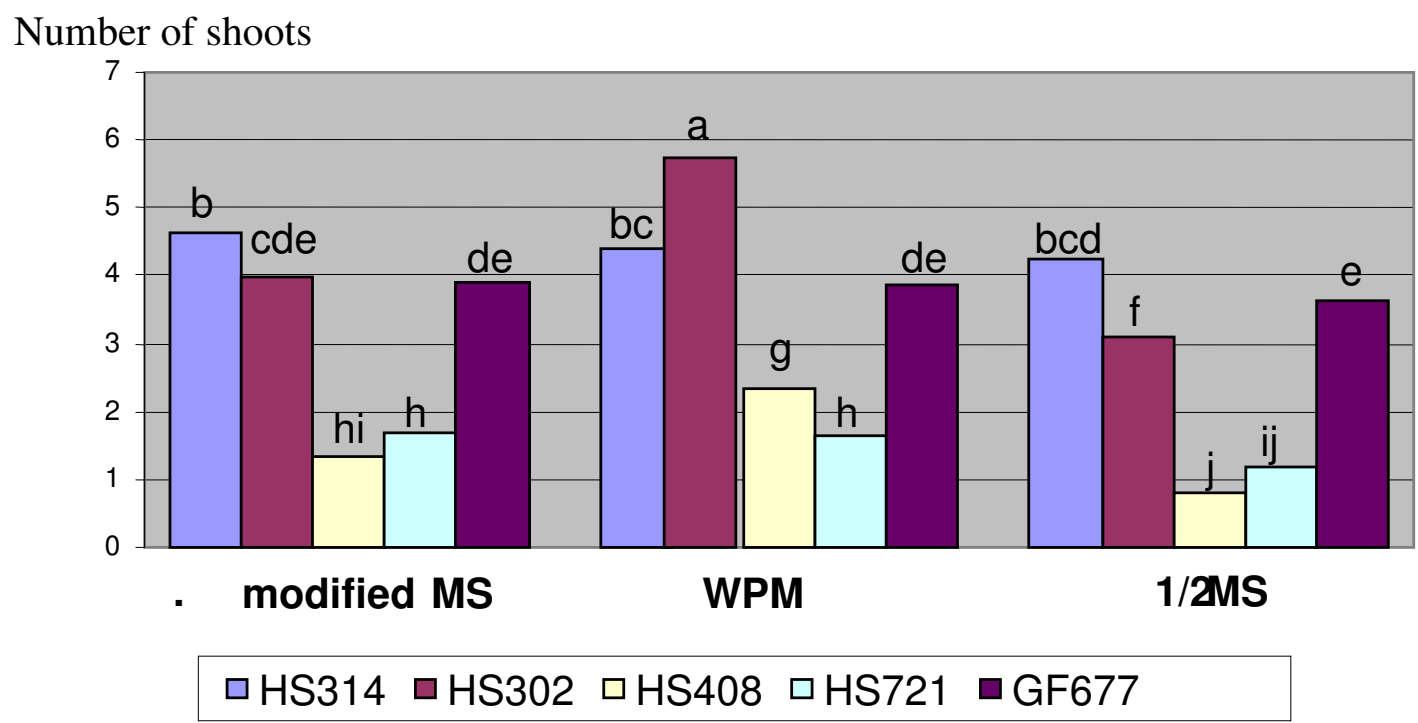

Fig 2.Meancomparison of the proliferationofseveralinterspecifichybrids of Prunuswith "HS314" in threedifferentmediumswithhormone ( $1 \mathrm{mg} / \mathrm{lBAP}+0.01 \mathrm{mg} / \mathrm{l} \mathrm{IBA})$. Means with same letters do not have significantdifference at $5 \%$.

The mean comparison of rootingpercentofhybrids by these two methods indicatedthat there was only a significant difference for HS302genotype $(\mathrm{P} \leq 0.05)$ between the used two methods. However, as it can be seenin Figure 4, theDipping the explant basesaturationmethod had induced more rooting percent for all genotypes.

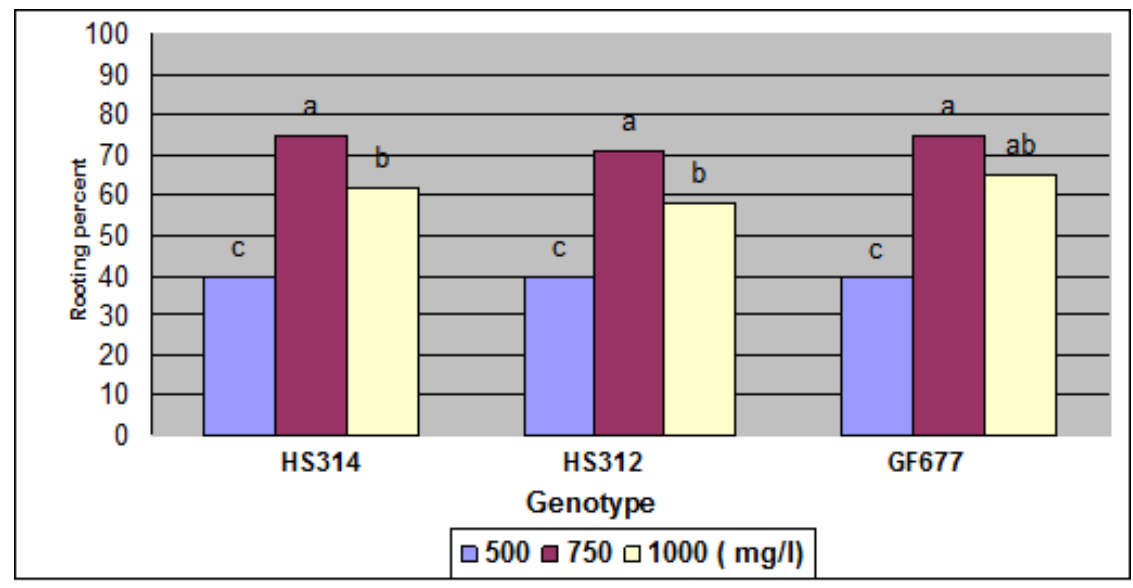

Fig 3: The rooting percent of peach $\times$ almond hybrids at three concentrations of IBA in modified MS medium using saturation method 


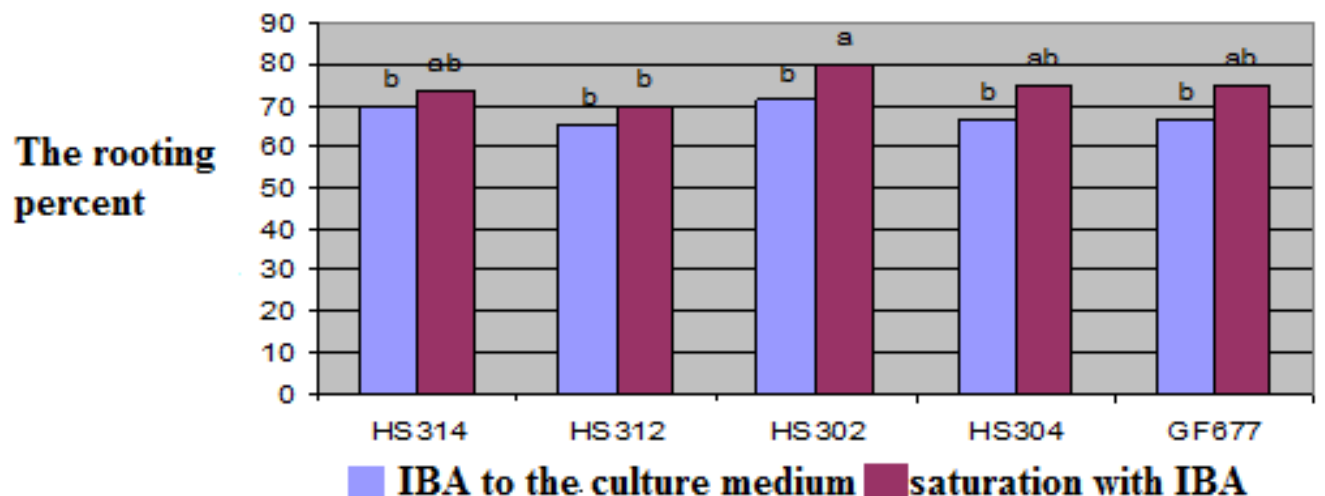

Fig 4- mean comparison of the rooting percent of interspecific hybrids of Prunus between twomethods of saturation with IBA and adding IBA to the culture medium

The meancomparison of rooting percent of hybrids between twomethods of saturation with IBA and adding IBA to the culture medium showed that there were significant differences $(\mathrm{P} \leq 0.05)$ between genotypes, hormonal concentrations and culture mediums (Figure 4). As seen in Figure 4, the saturation method had higher rooting percent for all genotypes.

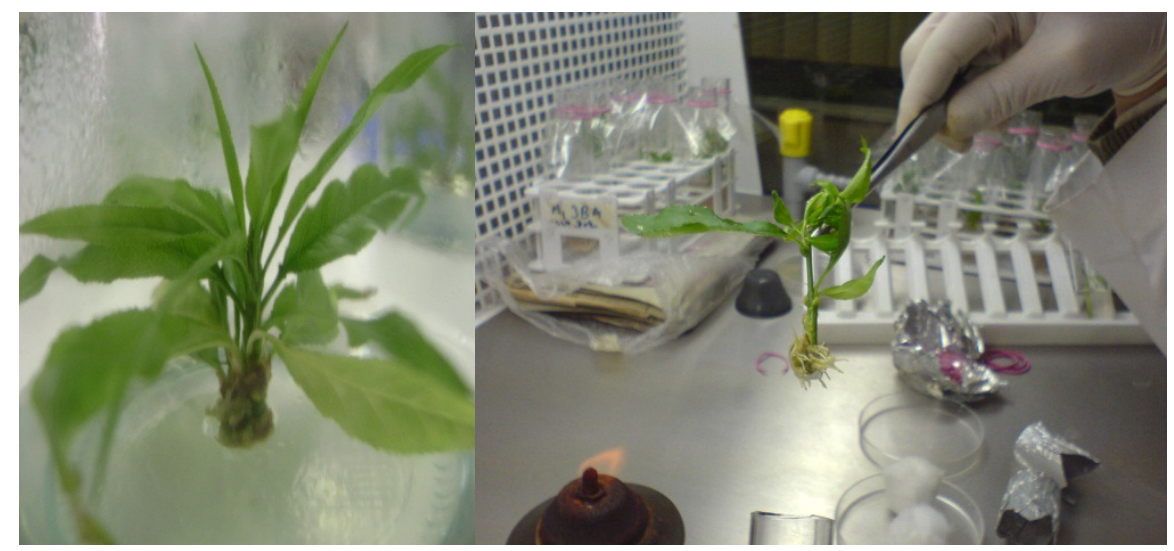

Fig 5- rooting of in vitro seedlings of HS314 hybrid

Theevaluation of vegetativepropagation indicated that this genotype had theability to propagate bycuttings and couldalsobe rooted. As theresultsshowed hormonal treatments of 1500-20000 mg/l IBA in Perlite medium had a rooting percent of 50-70\%, especially in early January, which was higher than GF677. The useofwoodycuttingswasmore advantageous due to easy handling, low costandno need for expensive equipments. Nevertheless, incase of availability of greenhouse facilities with temperature control and mistrooting system, working with herbaceouscuttingscouldbemore convenient. 


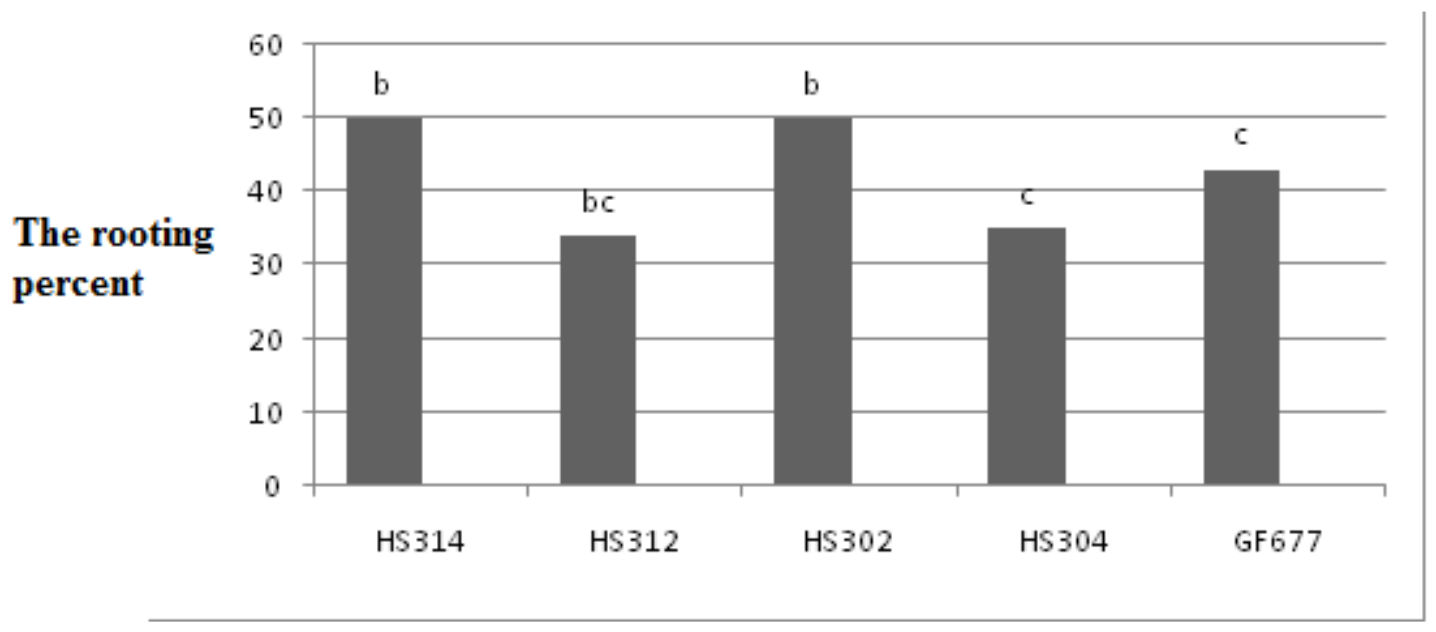

Fig 6.The mean comparison of rooting percent of "HS314" woody cuttings and some interspecific hybrids of Prunus in outdoors.Columns with dissimilar letters are significantly different at $5 \%$ level.

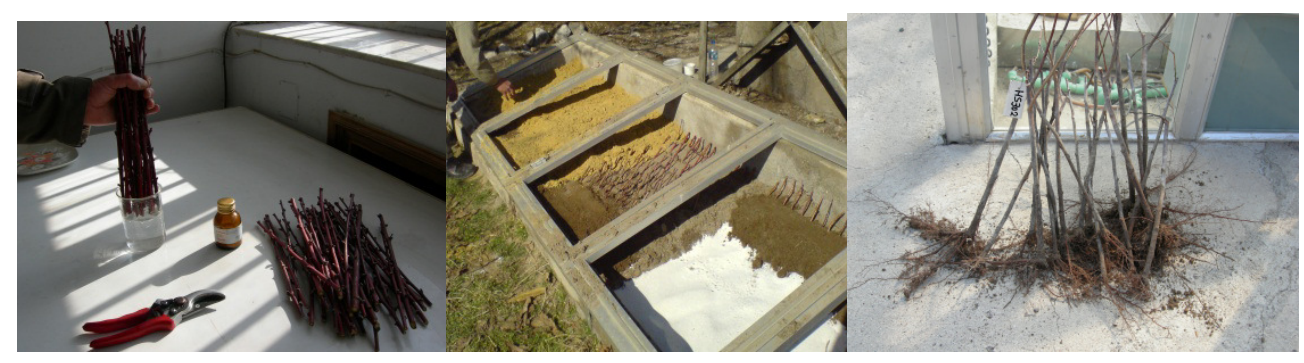

Fig 7.Implementing of the proliferation of hybrid "HS314" by woody cutting

The results indicated that there was a positive and significant correlation between the rooting percent of propagation through cuttings (in vivo) and micropropagation (in vitro). In other words, the genotype that had higher rooting percent by cuttings also showed this capability in in vitro cultures. Therefore, genotype "HS314" compared with other hybrids and GF677, which was used as a control in the experiment, had higher vegetative reproduction capability. The multi-year study showed that the roots' structure, shape and vigor of this rootstock was strong and wide, which would be more durable for cultivation in areas with low water, rocky and limestone soils and thus might induce better growth and yield for the tree.Therefore, this genotypes can be a very ideal rootstock for varieties of almonds, peaches, plums and apricots in the Mediterranean region, especially in Iran.

\section{REFERENCES}

Tatari, M.,Dejampour, J. and MousaviSA, 2013. Optimization of in vitro culture in Tetra, Nemaguard and GF677 clonal rootstocks.Journal of Crop Improvment, 17( 3) 103-115.
Rahnemoun ,H, Shekari, F, Dejampour, J, and Khorshidi, MB.2013. Salinity Effects on Some Morphological and Biochemical Changes of Almond (Prunusdulcis Mill.). Journal of Crop Improvment, 15(2).179-192.

Dejampour, J, Garigurian V, and Aliasgharzadeh, N. 2007.Sterilization ,establishment and proliferation for in vitro culture of some interspesific hybrids in prunus genus. Iranian journal of Horticultural Science and Technology.(3).165-174.

Dejampour, J, Garigurian V, and AliAsgharzadeh, N. 2007.Evaluation of some morphological characteristics and clonal propagation of some interspecific hybrids in prunus. Iranian journal of Horticultural Science and Technology.8(1).43-54.

Dejampour, J. Rahnemoun,H., Hassani,D., 2006. Breeding almond interspecific hybrid rootstocks in Iran.Acta Hort. 726: 45- 50.

Dejampour, J., Majidi, E., Khosravi, S., Farhadi, S., and Shadmehr, A. 2011. In vitro propagation of HS314 rootstock ( prunusamygdulus $\times P$. persica). HortScience 46(6):928-931. 
Dejampour,J, Aliasgarzade,N. Mehrshad Zinalabedini , Mehdi Rohaniniya and Eslam Majidi .2012. Evaluation of salt tolerance in almond (prunusdulcis L.) rootstocks. African Journal of Biotechnology ,Vol 11(56): 11907 -11912.

Beckman,T. G. and G. A.Lang.2003. Rootstock breeding stone fruits.Acta.Hort. 622. P.23-25

Channuntapipat, C., M. Sedgley, and G. Collins, 2003.Micropropagation of almond cultivars Nonpariel and $\mathrm{Ne}$ Plus Ultra and the hybrid rootstocks Titan $\times$ Nemagard. Sci. Hort. 98: 473 484.

Cos, J., D. Frutos, R. Garcia, J. Rodriguez and J. Garcia, 2004. Micropropagation of polliza V4 Cidaselection ,Acta. Hort. 658 : 197-202.

Cos, J., D. Frutos, R. Garcia, J. Rodriguez and J. Garcia, 2004. In vitro rooting study of the peachalmond hybrid Mayor, Acta Hort. 658 : 301-306.

Fotopoulos, S. and Sotiropoulos, T. E. 2005. In vitro rooting of PR 204/84 rootstock (Prunuspersica $\times P$. amygdalus) as influenced by mineral concentration of the culture medium and exposure to darkness for a period. Agronomy Research, 3(1), 3-8.

. Felipe, A. J., J. G. Mez. Aporisi and R. Socias. 1999. Breeding Almond $\mathrm{x}$ Peach hybrid rootstocks at Zaragoza. Proc. Of the First National Conference on Almond ( abstract book). Aug. 24-27. Shahrekord. Iran.

Kester, D. E., Asay, R. N. and Gradzil, Th. M. 2002.'Nickels' Almond $\times$ Peach hybrid clonal rootstock.Hort. Sci., 137 (2): 415 - 417.

Liu, W., Chen, X.S., Liu, G. J., Liang, Q., He, T. M., and Feng, J. R. 2007 b. Interspecific hybridization of Prunuspersicawith $P$. armeniacaand $P$. salicinausing embryo rescue. Plant Cell Tissue and Organ Culture 88 : 289-299.
Minev, I., and Balev, M. 2002. Interspecific hybrids of the Prunusgenus bred at RIMSA, Troyan, Acta Hort. 577: 195-198.

. Moreno, M.A., Tabuenca, M.C. and Cambra, R. 1995. Adesto 101, a plum rootstock for peaches and other stone fruit. HortScience 30:1314-1315.

Nicotra, A. and Moser, L. 1997. Two new plum rootsticks for peach and nectarines: Penta and Tetra. Acta Hort. 451:269-271.

Najafian, Sh., Rahemi, M., Tavallali, V., 2008.Effect of salinity on tolerance of two bitter almond rootstocks. American-Eurasian J. Agric. \& Environ Sci., 3 (2): 264-268.

. Okie, W.R., and Hancock, J.F. 2008. Plums, pp. 337358 Temperate Fruit Crop Breedeing.Springer, New York.

Pascal,T., Levigneron,A., Kervella, J.,and NguyenThe, C.1994. Evaluation of two screening methods for resistance of apricot, plum and peach to Monilinialaxa.Euphytica 77:19-23.

Perez - Tornero, O., Lopez, J. M., Egea J., and Burgos, L. 2000.Effect of basal media and growth regulators on the in vitro propagation of apricot (prunusarmeniaca L.) cv. Canino.Journal of Horticultural Science \& Biotechnology. 75 (3): $283-286$.

23. Renaud, R., and Salesses, G. 1994. Interspecific hybridization and rootstocks breeding for European plums.Acta Hort.359: 97-100.

. Son L and Kuden A (2003) Effects of seedling and GF-31 rootstocks on yield and fruit quality of some table apricot cultivars grown in Mersion. Turkish J Agric Forestry 27 (5):261-267

Tabatabaei, S.J., 2006. Effects of salinity and $\mathrm{N}$ on the growth, photosynthesis and $\mathrm{N}$ status of olive (Oleaeuropaea L.) trees. Sci. Hortic.101: 7-13. 